\title{
Quando a experiência de leitura é tema para a escrita'
}

\section{When the reading experience is subject to the written}

https://doi.org/10.34112/2317-0972a2021V39n81p15-30

Ilsa do CARMO Vieira GOUlart

RESUMO: O presente estudo assume por objetivo descrever uma prática de produção textual na universidade e compreender de que modo as experiências de leitura se mostram sinalizadas na ação escritora. Para isso, este trabalho realiza uma reflexão teórica, utilizando como corpus investigativo produções de textos de estudantes do curso de Licenciatura em Letras de uma universidade do sul de Minas Gerais, no período de 2014 a 2015. Os textos selecionados abordam como temática a narrativa de experiências de leitura. Desse modo, o trabalho toma como base teórica os estudos sobre os usos sociais da escrita de Soares e Street, a concepção de linguagem enunciativa-discursiva em Bakhtin, as discussões sobre produção de texto de Geraldi e a concepção de leitura de Barthes. A partir da reflexão proposta foi possível apresentar as experiências de leitura como um mote sinalizador de ações e relações de interlocução social que provocaram sentimentos e emoções no sujeito leitor-escritor.

Palavras-chave: Produção escrita; experiências de leitura; formação do leitor.

ABSTRACT: The present study takes aim to describe a practice of textual production in college and understand how the experiences of reading are flagged in action writer. For that, this job performs a theoretical reflection, using as investigative productions texts corpus of

1. Parte deste estudo foi apresentado no IV Simpósio Internacional de Ensino da Língua Portuguesa, realizado na Universidade Federal de Uberlândia em 2016.

2. Universidade Federal de Lavras, MG. 
students of Bachelor of Letters, an university from the south of Minas Gerais, in the period from 2014 to 2015. The texts selected deal with as theme the narrative of experiences of reading. In this way, the work takes as theoretical basis the studies on the social uses of writing and Street, the design may include language-discursive in Bakhtin, discussions about Geraldi text production and reading of Barthes. From reflection proposal was possible to present the experiences of reading as a mote of flag actions and social dialogue relations that provoked feelings and emotions in the reader-writer guy.

KEYWORDS: Written production; reading experiences; formation of reader.

\section{CONSIDERAÇÕES INICIAIS}

Diferentes trabalhos e pesquisas acadêmicas procuram compreender o processo de leitura e de escrita nas diferentes esferas da Educação Básica. Nas últimas décadas, alguns olhares investigativos se direcionaram para os modos de produção escrita no ensino superior e procuraram questionar as relações construídas com a prática escritora no processo de formação inicial de docentes, como os trabalhos de Lea e Street (1998), Castelhó e Mundó (2013), Marinho (2010), Rosa Fischer (2005), Adriana Fischer (2010), Fiad (2011), Simões e Juchum (2014), com a inquietação mais acentuada sobre o letramento acadêmico.

Destarte, o que se observa é que o processo de produção escrita nas diferentes áreas do ensino superior enfrenta desafios ímpares, diante de uma esfera de veiculação de textos em diferentes suportes, em que os sujeitos leitores e escritores convivem e interagem com a multimodalidade textual em contextos impressos e digitais. De acordo com Terra (2013), considerar o letramento como um conjunto de práticas sociais formalmente ligadas ao uso da escrita significa, sem dúvida, entender também que esse fenômeno detém uma história rica e multifacetada, não linear e cheia de contradições, que envolve importantes aspectos ainda a serem identificados para a sua melhor compreensão.

Partindo dessa perspectiva, este trabalho procura refletir sobre a prática de produção textual, com duplo objetivo: descrever uma atividade de produção textual realizada no ensino superior e compreender de que modo as experiências de leitura se mostram sinalizadas na ação escritora. Para tanto, realiza-se uma pesquisa de abordagem qualitativa a partir da análise exploratória, utilizando como corpus investigativo as produções de textos de estudantes do curso de graduação em Letras, 
de uma universidade do sul de Minas Gerais, especificamente na disciplina “Tópicos em Língua Portuguesa”, durante o período letivo de 2014 e 2015.

Visando melhor compreensão da proposta deste estudo, o texto está dividido em três momentos reflexivos: no primeiro, toma-se como base teórica os estudos sobre os usos sociais da escrita, de Soares $(2004 ; 2009)$ e Street (2007). No segundo, passa-se à concepção enunciativa-discursiva da linguagem com Bakhtin (2003; 2006), aproximando-se das discussões sobre produção de texto de Geraldi (1997) e da concepção leitura de Barthes (2004). No terceiro momento são apresentadas as produções de texto em interlocução com a reflexão teórica proposta.

\section{PrÁticas De LeTRAMENTO: ENTRE AS PERSPECTIVAS TEÓRICAS}

Os estudos de Soares $(2004,2009,2011)$ ao longo dos últimos vinte e seis anos têm contribuído para a compreensão do conceito de letramento. Sua proposição descreve letramento como o resultado da apreensão das práticas de leitura e escrita, em que a alfabetização e o letramento são compreendidos como processos indissociáveis, mas diferentes em termos de processos cognitivos, visto que ambos possuem certa especificidade.

Nesse sentido, ao pensar nos processos de leitura e escrita, Terra (2013) descreve que a associação imediata entre escolarização e letramento se deve ao fato de que a ideia de escolarização traz consigo a noção tanto de alfabetização, ou seja, aquisição e domínio do sistema de escrita alfabético, quanto a de uso social das atividades de ler e escrever.

Falar em escolarização parece óbvio para o senso comum; quando se fala em alfabetização e letramento, logo se entende que é na escola que se ensina e se aprende a ler e a escrever. Entretanto, para além do senso comum, crescentes evidências têm apontado que letramento e escolarização representam dois fenômenos distintos, cujas relações se ocultam sob considerável imprecisão, complexidade e obscuridade, como nos mostra Soares (2004).

Assim, de acordo com seus estudos, teríamos dois fenômenos distintos, que seriam o letramento escolar e o letramento social, pertencentes a um movimento maior que é a cultura escrita. Quando a criança ingressa numa instituição escolar, ela se depara com uma cultura escolar da escrita diferenciada daquela com a qual se relaciona.

A hipótese aqui é, então, que letramento escolar e letramento social, embora situados em diferentes espaços e tempos, são pertencentes aos mesmos processos 
sociais e oferecem elementos discursivos aos sujeitos-leitores, o que explicaria, em parte, por que experiências de leitura e escrita, proporcionadas pelo processo de escolarização, ampliariam a participação mais consciente e interativa em ambos contextos de letramentos.

Ao apontar uma via de orientação para a pesquisa sobre letramento escolar, Rojo (2000; 2001) procura discutir a relação intrínseca entre letramento e escola. Para a autora, a instituição escolar pode ser entendida como uma entidade de letramento, visto que nela ocorrem diferentes práticas de letramento, sejam orais ou escritas; seja por meio de textos impressos ou virtuais, devemos admitir a forma composicional do letramento escolar.

Um olhar prospectivo sobre o letramento impõe como indiscutível, em contextos educacionais, a ideia de que letrar ultrapassa a dimensão do código. Por isso, o grande desafio que se impõe ao letramento escolar, na atualidade, diz respeito à formação de um aluno que esteja preparado para o desafio imposto pelas complexas tecnologias das sociedades contemporâneas que demandam letramentos múltiplos (e multimodais).

As concepções de Brian Street (2007) também consideram que o ato de definir e de nomear é, em si mesmo, um dos aspectos essenciais dos usos do letramento, o que requer uma ação de cautela acerca dos termos escolhidos ao abordar essa temática. Nesse sentido, o autor apresenta descrições sobre o letramento de forma mais concreta, trazendo para a discussão as práticas de letramento desenvolvidos em vários países. Assim, Street (2007) considera que existem modos diferentes pelos quais representamos nossos usos e significados de ler e escrever em contextos sociais diversos; o testemunho de sociedades e épocas diferentes demonstra que é enganoso pensar em uma forma única e fechada sobre o letramento.

Outro aspecto que Street (2007) ressalta é que as práticas de letramento são constitutivas da identidade e da pessoalidade, a personhood. Segundo o autor, quaisquer que sejam os modos de usos da leitura e da escrita que venhamos a aprender, estarão relacionados a determinadas identidades e expectativas sociais a respeito de modelos de comportamento e papéis que poderão desempenhar na sociedade.

Primeiramente, os usos e significados do letramento em diferentes sociedades são semelhantes aos usos e significados do conceito de pessoa. Em segundo lugar, existe frequentemente uma relação fundamental entre os campos ideológicos de pessoalidade e letramento. Por isso, a representação do que vem a ser pessoa em contextos culturais específicos se efetiva, muitas vezes, pelos tipos 
de práticas de letramentos com as quais ela se compromete em determinados momentos ou ambientes sociais. Diante disso, letramento pode ser visto como uma circunstância relevante na própria definição de sujeito, na medida em que ser capaz de ler e escrever se torna um pressuposto na caracterização de uma pessoa socialmente competente, ativa e atuante.

Os estudos de Street (2007) asseguram que o letramento está constitutivamente relacionado com a pessoalidade. De acordo com a análise de uma pesquisa observada pelo autor, dois letramentos diferentes se destacam: o associado com o pronunciamento de sermões e o associado com a redação de cartas, e cada um envolve diferentes aspectos de pessoalidade e identidade. As cartas pessoais são associadas com afeto, situam o indivíduo num sistema socioeconômico de generosidade, sociabilidade e preocupação para com os parentes mais jovens (o que suscita admoestações e aconselhamento moral). Ainda segundo Street (2007), diferentes letramentos são associados a diferentes pessoalidades e identidades. Conjuntos semelhantes de associações podem ser vistos nesta cultura, uma vez reconhecida a importância do letramento para tais processos.

Quando frequentamos um curso ou uma instituição educacional, ou nos envolvemos num novo quadro institucional de práticas de letramento, por meio do trabalho, do ativismo político, dos relacionamentos pessoais etc., estamos fazendo mais do que simplesmente decodificar um manuscrito, produzir ensaios ou escrever com boa letra; na verdade, estamos assumindo ou recusando as identidades associadas a essas práticas. Isso quer dizer que uma pessoa cumpre diferentes funções na sociedade; em cada uma há determinados usos da linguagem, que constituem seus letramentos múltiplos. Numa determinada situação de interação comunicativa, pode-se estar desempenhando o papel de pai, por exemplo; já em outra, exerce-se o papel de professor, entre tantas atividades exercidas em comunidade. Ao contemplar práticas textuais em contextos variados, Street (2007) procura demonstrar a variedade e complexidade dos letramentos, pois o modelo ideológico considera as relações de poder e de ideologia desses diferentes contextos.

A reflexão a respeito do letramento social nos coloca diante do enredamento das relações ideológicas que o constituem, por isso, na seção seguinte, será abordada a concepção de linguagem que sedimenta este estudo, em proximidade com as discussões a respeito da prática de produção de texto. 


\section{A COMPLEXIDAde QUE ENVOLVE A COMPREENSÃo DA PRODUÇÃo ESCRITA}

Considerar a prática de produção escrita como mote de reflexão teórica requer abarcar a complexidade que envolve a linguagem materializada em palavras. Conforme Goulart (2012), a culminância da habilidade de escrever está em perceber que a ação escritora ocorre fora de uma condição de passividade, visto que se constitui num curso de atividades intensas, fruto de um processo ativo de criação e produção, de um pensar e repensar, de fazer, refazer e desfazer, de anizar e reanizar, de idas e vindas do sujeito em interação com a linguagem a ser expressa. Longe de ser considerado como um mito de inspiração inebriante, escrever, conforme Antunes (2005, p. 39), "é o resultado de muita determinação, de muitas tentativas, de muita prática afinal".

$O$ ato de escrever se mostra uma prática interdiscursiva que demarca seu espaço artístico e estético, alimentada por aspectos ideológicos, decorrentes de uma ação individualizada do escritor. Contudo, tal compreensão transita entre a atividade criadora isolada, que perpassa um processo solitário entre o escritor e a produção escrita, e a amplitude da coletividade, conforme descreve Bakhtin (2003, p. 125), que afirma que "o que se chama de 'individualmente criadora' constitui a expressão do núcleo central sólido e duradouro da orientação social do indivíduo”.

Assim, segundo Bakhtin (2003), o centro de anização de toda a atividade de produção textual não emana do interior dos sujeitos, mas do exterior, decorre do contexto social em que o sujeito está envolvido. Para o autor, a enunciação é o legítimo produto da interação social, ou seja, escrever se torna uma ação discursiva e dialógica. Para Bakhtin (2006), a sustentação vívida da linguagem está na comunicação dialógica dos sujeitos. Por isso, sua compreensão deve ocorrer por meio da metalinguística, por ultrapassar os limites da linguística. Usa-se da própria linguagem para compreendê-la.

No mesmo viés argumentativo, Olson (1991, p. 278) entende que a escrita é, por natureza, uma atividade metalinguística que pode ocorrer em dois níveis: o primeiro por ser uma forma de representação da língua, "faz da língua um objeto" de estudo dos aspectos lexicais, ortográficos ou sintaxe do texto produzido, remete à estruturação do texto em palavras, frases, períodos. O segundo nível se efetiva por meio de uma "metalinguagem oral" que, de acordo com Olson (199, p. 280), refere-se aos recursos linguísticos utilizados para "fazer referência ao conteúdo do texto". O autor assinala que a "metalinguagem oral" não se resume a uma reflexão 
a partir dos aspectos linguísticos disponíveis no texto, visto que a "metalinguagem oral pode analisar outras características da língua e do discurso, e também torná-los objetos da reflexão" (OLSON, 1991, p. 282).

Para Olson (1991), a metalinguagem inclui tanto conceitos verbais, como contar ou relatar algo, perguntar, responder, comentar, quanto conceitos nominais como história, falas, músicas etc., ações que tramitam tanto na oralidade quanto na escrita. Assim, para o autor, a escrita, como uma atividade metalinguística, parte da concepção de que a estrutura verbal se torna objeto do discurso e objeto da própria ação reflexiva.

$\mathrm{Na}$ tentativa de compreender a ação escritora, este estudo se impulsiona pelo mesmo questionamento feito por Antunes (2005, p. 28): "o que é o processo de escrever textos?” Para responder a esta questão, apresentamos a compreensão do ato de escrever a partir de alguns pontos conceituais. Primeiramente, como "atividade de interação", de intercâmbio social. Se a escrita se orienta em relação a um interlocutor, ela almeja e se constitui de acordo com o "auditório social", conforme nos mostra Bakhtin (2003). Na sua perspectiva, as palavras existem para o sujeito, seja este falante ou escrevente, em três aspectos: como decorrentes da língua, o que lhe atribui o caráter de ser pertencente a ninguém, mas de uso comum de todos; como alheias dos outros, repletas de ecos enunciativos; como minhas, caracterizando a possibilidade do sujeito utilizá-la em uma determinada situação e de um determinado modo, o que lhe confere uma expressão particularizada, como propriedade do sujeito. Nesse sentido, o fluxo da produtividade escrita decorre de um movimento dinâmico, ativo e interativo, segundo argumenta Goulart (2016, p. 160), balizado não por situações passivas nem lineares, mas antes "por tensões, por sentimentos ambíguos de contentamento e descontentamento, de consternação e prazer, de fluididade e truncamentos, de complementariedade e incompletude".

Por sua vez, Antunes (2005) descreve a escrita como "atividade cooperativa", em que a ação escritora acontece em conjunto com o leitor no processo de construção de sentidos e se efetiva a partir de uma "atividade contextualizada", ou seja, datada em um determinado tempo e espaço. A autora ainda esclarece que a produção escrita não ocorre de forma solta e aleatória, porque se trata de uma "atividade textual", visto que nos comunicamos por meio de textos, sejam verbais ou não-verbais, $o$ que faz da escrita uma "atividade orientada"; a partir de uma ideia central, tem-se uma meta que conduz o escritor a um determinado ponto de discussão ou reflexão, a uma "atividade intencionalmente definida". Para ela, a ação de escrever é uma 
atividade que envolve, além de especificidades linguísticas, outras, pragmáticas, o que determina as escolhas linguísticas e lexicais, pelo fato de ser uma "atividade que se manifesta em gêneros particulares de textos". A escrita em si não é uma atividade isolada; por ser "uma atividade que retoma outros textos", outros dizeres, ela se torna dialógica. Por fim, Antunes considera que escrever é uma "atividade em relação de interdependência com a leitura". Há uma relação de circularidade, na qual o que se escreve parte de leituras anteriores, da ação de se ler o próprio escrito e do princípio de que será lido por um dado leitor.

Por ser concebida como atividade adjetivada pela interatividade, pela cooperação, pela intencionalidade, pela orientação proposta e pela interlocução com outros textos, o ato de escrever se efetiva abalizado pela relação íntima com a leitura. Uma característica que se aproxima do que Barthes (2004) considera ser uma "aventura da leitura": a própria ação escritora. A leitura se mostra provocadora do desejo de escrever. A ação escritora se torna desejante pelo leitor, que almeja o desejo de escrever do autor e uma escrita semelhante, na ambição de ser uma escrita amada por outros leitores. Ainda segundo Barthes (2004, p. 22), o ato de escrever se faz “[...] o centro do processo da palavra”, entendendo o escritor que, ao efetuar a ação escritora, deve afetar, primeiramente, a si mesmo, porque, para o autor, escrever é "fazer coincidir ação e afeto, é deixar o escritor no interior da escritura".

A compreensão do ato de escrever parece demandar uma ação reflexiva do sujeito, em atividade interativa e discursiva, como sujeito agente da ação, mas que ao mesmo tempo se torna seu objeto direto; na composição das palavras é imediatamente afetado por elas, compondo e recompondo suas ideias, seus interesses e premissas. Nessa perspectiva, Geraldi (2007) considera o ato de escrever, numa relação de interlocução sob o qual traça algumas práticas possíveis, como a "definição de interlocutores", visto que pensar a escrita de um texto envolve a ponderação sobre a quem ele se destinará. Outra ação a ser acatada remete às "razões para se dizer", à motivação que impulsiona a escrita, aos pretextos que conduzem "o quê" e "para quê" se escreve. Desse modo, "ter o que dizer", para o autor, trata-se das experiências vivenciadas pelo sujeito, como ponto de partida para a produção textual para que, a partir daí, se possa ousar à reflexão de algo mais aprofundado.

Se a palavra possibilita a interação entre o mundo e eu, estabelece-se aqui a interação entre a atividade de leitura e a palavra escrita, ao descrever representações das experiências do ato de ler (GOULART, 2016). Assim, ao considerar 
o escritor como sujeito agente e atuante do seu processo de composição escrita, em que o ato de escrever se constitui como atividade interdiscursiva que desencadeia uma prática leitora, optou-se por apresentar as produções de texto desenvolvidas a partir das experiências de leitura vivenciadas por licenciandos, o que será descrito na seção seguinte.

\section{AS EXPERIÊNCIAS DE LEITURA COMO MOTE PARA A PRODUÇÃO ESCRITA}

Durante os semestres letivos de 2014 e 2015, foram desenvolvidas atividades de produção de narrativas, em forma de relatos de experiência, que deram origem a uma pesquisa qualitativa de cunho documental, que utilizou como corpus investigativo as produções de textos dos estudantes de graduação em Letras, especificamente, vinculados à disciplina de Tópicos em Língua Portuguesa ${ }^{3}$, de uma universidade do sul de Minas Gerais. A atividade de produção textual teve por finalidade proporcionar um momento de reflexão sobre as experiências de leitura um dia vivenciadas pelos próprios estudantes ${ }^{4}$, para posteriormente se estabelecer relações com a ação escritora.

Por ter como temática a prática de leitura vivenciada, descrita em forma de narrativas, os textos margearam outras discussões, mas priorizou-se alguns fragmentos entre cinquenta e cinco textos, que apresentaram representações do ato de ler a partir de relações com o contexto social em que estavam inseridos. Os fragmentos foram caracterizados a partir da análise de conteúdo que, segundo Bardin (2011), trata-se de um processo que compreende um conjunto de técnicas de análise da comunicação que utiliza procedimentos sistematizados e objetivos de descrição do conteúdo das mensagens, reunindo-as em unidades temáticas. Assim, selecionamos excertos aproximando-os por apresentarem "relações de interlocução do sujeito" com o ato de ler, ou por sinalizarem "relações de interlocução entre sujeitos", acompanhadas pelo ato de ler ou articuladas a ele.

3. Disciplina eletiva da Matriz Curricular do curso de licenciatura em Letras, no período de 2014 a 2015, com a ementa: "Concepções sobre letramento. Sociedade de cultura escrita e alfabetismo. Letramento como processo histórico-ideológico de aculturação. Letramento e escolarização. Estudo das práticas letradas não escolares e de seus respectivos modos de circulação. Reflexão sobre o impacto das novas tecnologias na natureza da linguagem e das práticas de produção e recepção de textos”.

4. Para manter a privacidade dos estudantes, optamos por não nomear os textos produzidos e classificá-los como T (Texto) seguido da numeração, conforme a ordem a serem apresentados. 


\section{RELAÇÕES DE INTERLOCUÇÃo DO SUJEITO COM O ATO DE LER}

Nas relações de interlocução do sujeito com o ato de ler se percebe uma escrita delineada a partir de marcações de atitudes e posturas que desencadearam uma ação leitora. As atitudes levavam o sujeito a uma experiência de leitura que se evidenciou na narrativa:

A entrada da leitura e da escrita em minha vida não foi diferente da maioria das pessoas: pequenos livros, pequenas histórias e uma grande fantasia! Sim, como toda criança que se apaixona pelo mundo da leitura, eu já fui princesa, sereia, animal, super-heroína, fada e por aí vai... Hoje, letrada e em constante aprendizagem, afirmo, sem nenhuma dúvida, que a fase mais brilhante da leitura e escrita é essa: quando você aprende. (T-1)

A primeira atitude se encontra na reflexão do ato de ler, uma ação reflexiva de algo vivenciado que remete o leitor-escritor a um encontro consigo mesmo por meio da escrita. A produção de texto se torna um espelho que reflete as imagens outrora ofuscadas, espaço de abalroamento em que, segundo Geraldi (1997, p. 166), “[...] o produto do trabalho de produção se oferece ao leitor, e nele se realiza a cada leitura, num processo dialógico cuja trama toma as pontas dos fios do bordado do tecido, pois as mãos que agora tecem, trazem e traçam outra história”. O que também podemos observar no próximo excerto:

Me colocaram ali, era castigo, eu errei. Me trancaram onde havia prateleiras de mundos - não que eu soubesse disso quando cheguei lá, mas logo eu descobriria - e eu em um momento de tédio fui acariciar esses "porta-mundos". Meus dedos removiam a poeira que havia em cada um deles, e minha melhor amiga, a curiosidade, me convidava a tirar um desses mundos para conhecer, mas não demonstrei tanto interesse. Até que o vi... Era vinho, letras douradas, um menino magricela com óculos, montado em uma vassoura. Meus olhos perfuraram aquele livro, aquele mundo que estava preso em meus dedos. Algo diferente estava acontecendo.

Uma palavra, "magia", e a curiosidade não se controlou, se jogou, e me jogou para dentro daquelas páginas. Um mundo novo se fez, e eu não estava mais de castigo, as prateleiras de mundos deram lugar a um mundo único e eu não estava mais trancada. Eu estava livre, livre a viajar por um mundo que já estava pronto, mas que permitia criar, criar momentos, memórias, vidas e sonhos. (T-2) 
Neste fragmento, igualmente se visualiza a atitude reflexiva da ação leitora, que permite um espaço introspectivo que inaugura um (re)encontro com o vivido, em que o escritor assume a posição de primeiro leitor do texto, pois para Geraldi (1997, p. 167), a "produção deste, leitor, é marcada pela experiência do outro, autor, tal como este, na produção do texto que se oferece à leitura, se marcou pelos leitores que, sempre, qualquer texto demanda". E é esse movimento de leitura a partir da interação que configura $o$ ato de escrever como processo de interlocução.

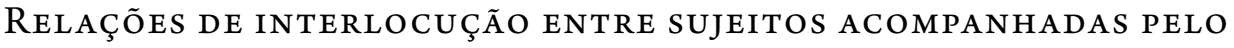
ATO DE LER OU ARTICULADAS A ELE

As relações de interlocução entre sujeitos que acompanham e articulam as ações entre leitores se mostram delineadas por atividades de partilha, de cooperação, de troca, em que "o acesso da escrita é também um acesso a estas estratégias que resultam de relações interlocutivas do passado, de seus objetivos (razões para dizer) e das imagens de interlocutores com que aqueles que escreveram pretenderam um certo tipo de relação". (GERALDI, 1997, p. 183).

Tem assuntos na vida que nos fazem mergulhar no passado como um mergulho num mar desconhecido. Neste caso, não num passado desconhecido, mas num passado que todas as vezes traz boas e novas recordações. Mamãe há muitos anos atrás já era professora. Ainda é. Eu pequenina já tinha incentivo à leitura por ter livros em minha casa lá no bairro Piteiras. Era uma casa simples e pequena, mas cheia de sabedoria, sabedoria trazida por Catarina, minha mãe que sempre deu aqueles empurrõezinhos para viajar no mundo da leitura e da escrita. ( $\mathrm{T}-3)$

A escolha e o modo de anização das palavras e expressões, ou seja, dos enunciados que compõem um texto, permitem desencadear as emoções vividas. Em T-3, as repetições de palavras não são aleatórias, tornam-se uma estratégia de reforço da ação, porque, segundo Geraldi (1997), a configuração de uma narrativa não se restringe a um cumprimento de normas, mas por aquilo que se narra.

Lembro-me como se fosse ontem, da mão que me conduzia para um caminho sem volta. Quando ela me deixou, senti medo, não queria de maneira alguma que me deixasse. Não entendia o porquê de tamanha maldade, era o que eu pensava. Deixar-me ali junto 
com outras crianças diferentes e que eu nem conhecia, foi tudo muito estranho, mas havia uma pessoa entre elas, era grande (a meus olhos de menina), me abraçou e me colocou ali sentada juntamente com as outras crianças. (T-4)

A primeira experiência com a leitura, que me marcou, foi quando me tornei a primeira aluna do pré-escolar a saber ler. Me lembro que um dia eu estava sentada na escada de entrada da escola lendo um livrinho. Foi quando minha professora chegou atrás de mim e ficou por algum tempo me observando sem eu saber quando me virei e a vi, ela estava em lágrimas, muito emocionada por ver uma aluna tão pequena lendo em tão pouco tempo. ( $\mathrm{T}-5)$

As experiências acima transcorrem de um ambiente escolar; as situações que aparecem descritas nas narrativas provocam uma atividade metalinguística, não tanto por proporcionarem, segundo Geraldi (1997, p. 191), uma reflexão analítica sobre os recursos expressivos: “[...] estas atividades produzem uma linguagem, (a metalinguagem) mais ou menos coerente que permite falar sobre linguagem, seu funcionamento, as configurações textuais, o léxico, as estruturas morfológicas e entonacionais". Entretanto, remete-se ao fato de a metalinguagem incluir "conceitos verbais", pois, conforme Olson (1991), utilizamos o nível da "metalinguística oral" por acionar a capacidade de narrar, de expressar ideias, pensamentos e vivências, a partir de uma reflexão em que "recursos para a referência aos atos da fala", como asserções, hipóteses, conclusões, especulações, suposições, entre outras, podem contribuir com a elaboração de determinados textos, em que é possível conjeturar um pensamento mais elaborado e refinado na escrita, considerada uma ação significativa no processo educacional.

Todo dia, no mesmo horário, tínhamos este ritual, sentados à mesa, papai do lado e mamãe da cozinha só observando, atração diária que tinha como público: irmão, avós, cachorro, papagaio etc. $O$ processo de aprendizagem da leitura foi uma etapa marcante em minha vida, pois, diferente da maioria dos meus colegas de classe, fui a última a conseguir a ler. Meus pais, principalmente meu pai, faziam de tudo para que eu pudesse finalmente adquirir a leitura. (T-6)

Era mais uma manhã de domingo, do silêncio do dia que estava nascendo, deitava ainda em minha cama, esperava o barulho da porta se abrindo, quando meu pai chegava com 
seu jornal. Pegava minha cobertinha, ia para a sala e ao lado dele pegava minhas páginas favoritas e lá estavam as crônicas do José Simão. Não consigo me lembrar exatamente a idade que me despertou esse interesse em ler, mas não me esqueço desse incentivo que tive por anos. (T-7)

As experiências de leitura vivenciadas em ambiente não escolar, aqui apresentadas, ressaltam outro aspecto relevante das relações de interlocução: as relações de afetividade, que perpassam as duas representações das relações construídas em experiências de leitura. $\mathrm{O}$ vivenciado afeta o sujeito-escritor, pois a experiência é o que se experimenta, o que se prova, o que toca, conforme Larrosa (2002). Um mote que se torna o centro, o protagonista da produção escrita, conforme Barthes (2004), situa-se num plano de reciprocidade, move-se afetando o sujeito-escritor ao mesmo tempo que é afetado pela escritura.

\section{CONSIDERAÇÕES FINAIS}

Este trabalho teve como objetivo apresentar uma prática de produção textual na universidade e compreender de que forma as experiências de leitura se mostram sinalizadas na ação escritora. Desse modo, considerou-se que o ato de ler proporciona ao sujeito a possibilidade de interação e de interlocução com textos e com outros sujeitos por meio da palavra escrita. O leitor, longe de uma recepção marcada pela passividade, é considerado um ser ativo que atribui sentido ao texto e às relações que permearam a leitura realizada. Assim, a palavra escrita ganha significado a partir da ação do leitor-escritor que retoma o vivenciado e o ressignifica.

A reflexão a partir dos excertos de textos produzidos por estudantes de graduação nos mostra que é na diversidade de situações vivenciadas que ocorrem relações de interlocução do sujeito com o ato de ler, ou entre sujeitos a partir da ação leitora. Essas ações e atuações são significativas no processo de formação do sujeito-leitor e do sujeito-escritor, contribuindo com o processo de letramento.

Cada atividade vivenciada pelos sujeitos se constitui uma operação de produção de sentidos, como nos mostram os estudos de Goulemot (2001, p. 108), em que a leitura pode ser compreendida como um ato de produção de sentidos, entendendo que "ler é, portanto, constituir e não reconstituir um sentido"; da mesma forma, a produção textual se constitui demarcada pelo processo de produção de sentidos pelo escritor, conforme Geraldi (1997). 
Embasados nessa perspectiva teórica, verificou-se que, quando o sujeito-escritor produz um texto, também se ativa sua capacidade leitora, pois, ao ler, sua produção está agindo com e sobre o texto, anizando as palavras, compondo os enunciados e produzindo-lhe os sentidos almejados. Ler é um ato tão produtivo quanto escrever, visto que o texto é recriado, reconstruído pelo leitor-escritor; ambas as ações estão interligadas e, de alguma forma, atreladas às variadas circunstâncias que o cercam. Verifica-se que ocorrem transformações e enriquecimentos do escrito, visto que, no momento da leitura, o leitor-escritor está em trabalho intelectual e afetivo, tanto no plano social quanto no plano individual. Nesta exploração oral e/ou escrita está se produzindo outros textos a partir do texto lido. O sujeito leitor-escritor deve ser encarado como produtor e não como repetidor passivo do que leu, por ser acionada a "metalinguística oral", ou seja, as inferências, as asserções, as conclusões, as reflexões que ocorrem durante todo o processo de produção escrita (OLSON, 1991).

Portanto, entendemos que é necessário compreender a atividade de produção escrita como esfera de atuação dos conhecimentos do código linguístico, mas também como espaço de participação crítica, reflexiva e ativa do sujeito-escritor e do sujeito-leitor em seu contexto social. Assim, por meio da compreensão e posicionamento argumentativo na escrita, assume-se a condição de leitor-escritor em experiências de letramento. $\mathrm{O}$ que demanda das instituições escolares, no caso, as de ensino superior, oportunizar situações em que os estudantes possam expressar-se pela linguagem escrita, como forma de compreensão de si mesmo, do outro e do mundo que os cerca.

A relação entre a leitura e o contexto social do estudante graduando nos aproxima da concepção de Paulo Freire (2000) sobre o ato de ler, quando descreve que há precedência da ação leitora nas vivências e nas relações com o mundo antes da apreensão do código. Tal preceito se evidencia nas experiências de leitura narradas, em que muito antes de se conhecer ou se dominar o código da língua escrita, ocorre uma leitura envolta de relações interlocutivas entre o sujeito e a obra, entre sujeitos e tudo o que está a sua volta, de maneira única. Criam-se espaços de vivências, em que as práticas de letramento são constitutivas de uma dada identidade, de uma dada pessoalidade, repercutindo numa experiência de leitura que se mostrou tema inspirador à escrita.

\section{REFERÊNCIAS}

ANTUNES, Irandé. Lutar com palavras: coesão e coerência. São Paulo: Parábola Editorial, 2005. 
BAKHTIN, Mikhail Mikahailovich. Estética da criação verbal. Tradução Paulo Bezerra. São Paulo: Martins Fontes, 2003. . Marxismo e filosofia da linguagem. Tradução Michel Lahud e Yara Frateschi Vieira. São Paulo: Hucitec, 2006.

BARDIN, Laurence. Análise de conteúdo. Portugal: Edições 70, 2011.

BARTHES, Roland. Rumor da língua. Trad. Mário Laranjeira. 2. ed. São Paulo: Martins Fontes, 2004.

FIAD, Raquel Selek. A escrita na Universidade. Revista da ABRALIN, v. Eletrônico, n. Especial, p. 357-369. 2011. $2^{a}$ parte. Disponível em: https://revista.abralin./index.php/abralin/article/ view/1116. Acesso em: 10 maio de 2021.

FISCHER, Rosa Maria Bueno. Escrita acadêmica: arte de assinar o que se lê. In: COSTA, Marisa Vorraber; BUJES, Maria Isabel Edelweiss (s.). Caminhos investigativos III: riscos e possibilidades de pesquisar nas fronteiras. Rio de Janeiro: DP\&A, 2005. p. 117-140.

FISCHER, Adriana. Os usos da língua na construção de sujeitos letrados: relações entre a esfera escolar e a acadêmica. Acta Scientiarum. Language and Culture, Maringá, v. 32, n. 2, p. 215-224, 2010. Disponível em: https://periodicos.uem.br/ojs/index.php/ActaSciLangCult/article/ view/9257/9257. Acesso em: 10 maio de 2021.

FREIRE, Paulo. A importância do ato de ler: em três artigos que se complementam. 15. ed. São Paulo: Cortez, 2000.

GERALDI, João Wanderley. Portos de passagem. São Paulo: Martins Fontes, 1997.

GOULART, Ilsa do Carmo Vieira. As palavras e seus “mistérios”. Revista Linha Mestra, Campinas, n. 21, p. 402-407, ago./ dez., 2012. Disponível em: https://linhamestra3o.files.wordpress. com/2017/02/lm_16_12_c2.pdf. Acesso em: 10 maio de 2021.

. A relação entre o escritor e a produção escrita no viés da dialogicidade e interatividade. Revista Letras, Santa Maria, v. 26, n. 52, p. 159-176, jan./jun. 2016. Disponível em: file://C:/ Users/MARCOS\%2oGOULART/Downloads/25329-119938-1-PB.pdf. Acesso em: 10 maio 2021. GOULEMOT, Jean Marie. Da leitura como produção de sentido. In: CHARTIER, Roger. Práticas de leitura. São Paulo: Estação Liberdade, 2001.

LARROSA, Je. Notas sobre experiência e o saber de experiência. Revista Brasileira de Educação, Rio de Janeiro, n. 19, p. 20-28, 2002. Disponível em: https://www.scielo.br/pdf/rbedu/n19/n19ao2. pdf. Acesso em: 10 maio 2021.

MARINHO, Marildes. A escrita nas práticas de letramento acadêmico. Revista Brasileira de Linguística Aplicada, Belo Horizonte, v. 10, n. 2, p. 363-386, 2010. Disponível em: https://www.scielo.br/scielo. php?script=sci_arttext\&pid=S1984-63982010000200005. Acesso em: 10 maio de 2021.

MATENCIO, Maria de Lourdes Meirelles. Leitura, produção de textos e a escola: reflexões sobre o processo de letramento. Campinas: Mercado de Letras, 1994.

OLSON, David R. A escrita como atividade metalinguística. In: OLSON, D. R.; TORRANCE, Nancy. Cultura escrita e oralidade. Tradução Valter Lellis Siqueira. São Paulo: Editora Ática, 1991. p. 267-286.

SIMÕES, Luciene Juliano; JUCHUM, Maristela. A escrita na universidade: uma reflexão a partir do que os alunos dizem em seus textos. SIELP, 2014, Uberlândia. In: Anais do SIELP. Vol. 3, n. 1, Uberlândia: EDUFE, 2014. Disponível em: http://www.ileel.ufu.br/anaisdosielp/. Acesso em: 08 set. 2016. 
SOARES, Magda. Letramento e Escolarização. In: RIBEIRO, Vera Masagão (.). Letramento no Brasil. São Paulo: Global, 2004. 287 p. . Letramento: um tema em três gêneros. 3. ed. Belo Horizonte: Autêntica: 2009. 124 p. . Alfabetização e letramento. 6. ed. São Paulo: Contexto, 2011. 123 p.

ROJO, Roxane. Letramentos múltiplos: a escola e a inclusão social. São Paulo: Parábola, 2009. . Letramento escolar, oralidade e escrita em sala de aula: Diferentes modalidades ou gêneros do discurso? In: SIGNORINI, I. (.). Investigando a relação oral/escrito e as teorias do letramento. Campinas-SP: Mercado de Letras, 2001. p. 51-74.

STREET, Brian. Perspectivas interculturais sobre o letramento. Revista de Filologia e Linguística Portuguesa da Universidade de São Paulo, São Paulo, n. 8, p. 465-488, 2007.

TERRA, Márcia Regina. Letramento e letramentos: uma perspectiva sócio-cultural dos usos da escrita. Revista DELTA, São Paulo, v. 29, n. 1, p. 29-58, 2013. Disponível em: https://www.scielo.br/scielo. php?pid=So102-44502013000100002\&script=sci_abstract\&tlng=pt. Acesso em: 10 maio de 2021.

\section{SOBRE A AUTORA}

Ilsa do Carmo Vieira Goulart. Doutora em Educação pela Faculdade de Educação da Universidade Estadual de Campinas. Integrante do grupo de pesquisa ALLE - Alfabetização, Leitura e Escrita.

E-mail: ilsa.vieira@uol.com.br.

Recebido em 02 de janeiro de 2018 e aprovado em o7 de maio de 2021. 